\title{
Research on the Network Public Opinion Crisis Management and Its Governance Principles in Universities
}

\author{
Ke JIANG
}

School of Public Management, Yunnan University of Finance and Economics, Kunming, P.R. China

1341824069@qq.com

Keywords: University crisis, Network public opinion, Crisis management, Governance principles.

\begin{abstract}
With network technology development, the network becomes the main tool for people to get information from outside and express opinions or suggestions. Network public opinion is an important matter on the response to social problems. Therefore, the primary task of maintaining social stability is managing network opinion. As an active space of network public opinion, the network public opinion in universities has similarities and differences with others. To deal with the crisis of network public opinion in universities, the management of public opinion should adhere to three basic principles: responsibility, information disclosure and guidance.
\end{abstract}

\section{Introduction}

With the emergence of network media and its rapid development, some emergency incidents will become hot spots and focal points fast of public opinion on the net. Without the effective guidance and management, the negative network public opinion will spread fast by network. Finally, it causes network public opinion crisis and even some negative impact on society. The establishment of campus network space provides a growing environment for network public opinion. As campus service providers and affairs administrators of functional departments of colleges and universities, we should minimize negative impacts caused by university network public opinion crisis through scientific and effective methods of network public opinion regulations, and finally create a harmonious environment for campus network public opinion. All these request for the management of functional departments at colleges and universities. This is an important content to strengthen campus management, and also a big problem.

\section{The mutual effect between network's crisis and the management of public opinion}

The 33rd internet development condition investigation report of China Internet Network Information Center (CNNIC) indicates that the number of Chinese internet users reached 564 million, for a grand total of 53.58 million new internet users; the Internet penetration rate is $45.8 \%$ up to the end of December 2013, which remaining slow growth. [1] Thus Internet industry becomes the interactive communication platform, especially being loved by college students. Network infiltrates into all aspects of colleges, forms the information campus, and becomes indispensable parts of college students' study and life. The concentrated emergency and occurring of network public opinion in colleges and universities affects college students' outlook on life, world outlook and values.

The "digitalization" and "virtualization" of network changed people's traditional mode of daily lives, the government-led single opinion developed multicenter pattern of public opinion. The Internet not only improved the interactions between people, but formed its network structure with open, interactive, communicative, and free features. Thus it has the functions of information interaction, public opinion expression, public will converge, and others, which can show the public opinion expression and freedom of speech, and overcome the shortcoming of the traditional news media.

Network extends to every corner of the colleges and universities, which forms a campus specific public network and also provides realistic foundation for network public opinion. Since 2000, universities have started to speed up the construction of digital campus. Most of the nation's 
colleges and universities have established their own campus network, built the teaching management system, administrative office system and scientific management system. Meanwhile, students have independent learning with the campus network, and choose their favorite courses, spreading knowledge and enhance learning motivation. Teachers can exchange the teaching experience and enhance the teaching. Most importantly, network eliminates the gap between the teachers and students, which promotes the discussion and communication on teaching and learning, develops campus network, but causes new problems.

Network becomes instant intersection place of speech. The campus network is one of the most active areas. College students' high attention and large amount of information release combined with the freedom, sharing, personalized and openness of campus network makes the Internet a highly open community. Every student can show information, opinions, and comments. Because of lacks of management and corresponding rules and regulations, the randomness of information dissemination enhanced. Compared with other networking groups, the campus network is more likely to cause public opinion crisis.

Network public opinion becomes the inevitable outcome of campus network, and important factors affecting campus network environment. To know network public opinion of colleges, the first thing to do is to clarify its connotation. The narrow sense refers to "the sum of various emotions, wishes, attitudes and opinions held by higher education college students and workers on all public affairs they care about and other people's caring affairs, including higher education." [2]

Network public opinion of universities is different from general public opinion, and these two have obvious differences in nature. It mainly resulted in different subjects and network environment:

1) Different subjects of public opinion. Thus network public opinion of universities is the inevitable product of special institution circumstance. College students are different from other groups, which makes this group more secretive, fast and concentrated. Therefore, the management cannot be equal to that in general public opinion's. The management for college students as a special subject of public opinion creates difficulties in public opinion management.

2) Different background. Compared with public opinion crisis in other network space, universities' network is usually local wireless network. Campus network public opinion occurs in a closed space, it is different from other network management on methods, technology and personnel configuration. The main network service providers are students and teachers, and services are mainly on corresponding rules for campus environment, network access speed, access channel and scope.

3) Different concerned contents. Social hot spots easily become topics in the public space, and the focus scope of college students is bigger. There are many social hot topics coming from college students' focus. College students pursue ideal, and be good at discovering details of life, so they are easy to resonate with each other, create a variety of speech on campus, and finally become social hot issues. On the other side, network public opinion of colleges as intersection space, because of its academic, speech environment relatively loose and tolerance, it focuses on social frontline issues.

Network public opinion of colleges has the inner running mechanism; the management process is likely to fail. College students have different thoughts, emotions, values, and psychological demands. Under this background, network public opinion is born. The uniqueness of college students also cannot be ignored in the process of public opinion management.

\section{The action dilemma of network public opinion crisis in universities}

Network public opinion crisis makes managers realize its necessity. Every institution established their own network information center. With the development of the network and its technology, this center not only has the function of network construction, and gradually to network management. Although the status of management department in colleges and universities are rising, network era brings new problems. The action of network public opinion crisis suffered inadequate attention of management departments, insufficient management ability, lack of communication and coordination with each other. 


\section{Management department with inadequate attention}

Network public opinion differs from campus management affairs, belonging to management by exception for emergencies. There's no enough attention on management which only stays in crises caused by passive processing network public opinion. Teaching, scientific research and management of network public opinion are equally important. When universities start to transform the developing concept, they focus on improving the competitiveness of colleges and universities, but ignoring the construction of "soft power". Network is a "double-edged sword", and its positive role is to promote campus development that may bring new problems: how to block bad information, how to distinguish right and wrong, how to construct campus network culture, etc. [3]

Network environment plays roles in many aspects, especially in the formation and development of value or moral concept. The network's characteristics and transmission law can affect college students' learning and life, and the process is very long and profound. University is the important base for personnel, and the inadequate attention of management departments will affect the cultivation of talents.

\section{Needing the improvement of management ability}

Network public opinion is a new kind of power, campus network with different comments raises new challenges to its management. Network supervision and maintenance have to be promoted.

Network can beyond the limitations of realistic social, and crisis management of social network public opinion is the social management problem. Due to its lack of direct restriction of laws and regulations, some people give irresponsible, negative and false comments by network platform, which caused public opinion crisis. When we face the problem, the management needs to solve it in two aspects: first, the management system is mainly for technical management, which lacked contingency plans for emergencies and failed to establish a unified and comprehensive system. It prevented the establishment of management system; second, there's a disconnect between the management mechanism of university network public opinion and practical problems, and weak links in network regulations.

Above all, researches mainly stay on establishing campus emergency preplan, and few on how to perfect management mechanism of network public opinion. The research scopes mainly focus on the campus network BBS. The result considered that management mechanism was not perfect, daily management system is not sound, and managerial subject and object is not clear. But academics give the answer to build clear duties of network management department, or establish a particular management sector. Relying on a certain department to assume part managerial responsibilities is difficult to leverage their capabilities.

\section{Lack of communication and coordination management}

Facing complicated network environment, there is lack of interactive communication between the management and students. Managers focus on releasing multiple-information by technologies, even if the public opinion is positive, but we cannot effectively achieve it. Unobstructed information communication channels are for college students to accept teaching, prevention ideas and management. But colleges and universities gradually become government organizations, managers and the managed are lack of communications. Meanwhile, schools can manage network hardware facilities. They manage and limit students' network behaviors by timely monitoring, resources advantage, organization and management advantages. It's good for guiding, but the mandatory management is still unequal.

Untrue network information and its lack of effective regulation further lead the lack of effective communication. College students also can appear as an anonymous to discuss topics on the internet. As described above, managers can't manage campus network by rules. During the transitional period of society, managers are influenced by traditional education concept, and they often take college students as being educated or managed person. Network is more acted by "agenda-setting" and "the silence spiral" force, so university public crisis is less controllable. 


\section{The governance principles of university's network public opinion crisis}

University's network public opinion crisis is a new crisis under new informational conditions. From sociological perspective, one of the most important reasons causing network problems is that network society is still in a state of "uncontrollable disorder". To make network society develop reasonably, orderly, healthy, and stably, we must use the power of network management to limit and eliminate problems and chaos caused by network activities. To establish and maintain the normal order of network society.[4] Therefore, some basic governance principles in the management of network public opinion seems extremely important when dealing with the crises.

\section{Responsibility principle}

Responsibility means dealing with the body of university public crisis, and it is the first step to solve crises.

Responsibility principle becomes the inevitable stage of effective management function. Colleges and universities are exposed to social risks; inadequate management can cause some negative opinions on schools. The only solution is calming down and reducing the negative effects of public opinions quickly, which requires functional sectors to know rationally the nature of opinion. In addition, we should hold positive attitude in response to negative rumors. Especially the main leaders of the colleges and universities, they must firstly assume responsibilities. This can show their sincere hope to solve events, and they're willing to take corresponding responsibilities. After that, some irrational remarks can be reduced apparently, and public opinion pressures can also be eliminated. This creates a good condition to reset issue and balance public opinions for universities. If we withhold information and forbidden to discuss related news by executive order layers, the strong desire of public may be relatively quiet momentarily, but cannot be calm. When public opinions gradually accumulate to relatively unified extent, it will point to colleges and universities. Therefore, responsibility is the primary strategy of facing the network public opinion in colleges and universities.

\section{Information disclosure principle}

Ensuring everyone getting the truth is the precondition of information disclosure principle. Network society is an information supermarket. The transmission of network society information is more convenient and multipath, suppression of information transmission is hard to do technologically. Blockading news is stupid, and the results tend to be counterproductive. Once the event happened, the lack of authoritative information's releasing will make things more complicated. Others may explain the event according to their one-sided reports, which provides opportunities to different public opinions for different events. Network is an active access to information, and people always take those about themselves and they interested in. College students are easy to accept new thinking, and choose views closed to their thoughts. There's lack sharing different experiences. Different explanations on the network spread over a period of time, and soon will be developed toward extreme direction. It is impossible to control public opinions. When negative public opinions appear, schools should sincerely publish the information, prevent the spread of the gossip going around, and dissolve the anger timely. We should create good conditions for resetting issue, guiding directions and resolving crises.

\section{Guiding principles}

Equal communication is the important measure to solve public opinions. The status of information monopoly is nonexistent, and information discourse monopoly power is deconstructed by interactive dialogue. In the network, opinion leaders are in charge on the information, and they are also victors in the struggle of the words power. But this is a temporary victory; the struggle will not be ended quickly owing to the victory of a party. There's no one can be eternal opinion leaders. Therefore, it is important for solving opinion crisis to struggle words power and set up public opinion issues. [5] The way of changing passivity to activity is to do the above things. Compared with college students, schools have absolute advantages in network resources possession. If we take 
full use of rheological laws of words power, and actively use mainstream network for voice, we will have the ability to rebuild the dialogue structure by publishing information. Put events to the public, and transform people's anger to events' nature, and then lead people's rational thinking. Then we can balance one-sided public opinions, and opinions' direction can develop positively.

\section{References}

[1] CNNIC releases 33 times. The Chinese Internet network development state statistics report, 2014. http://www.cnnic.net.cn/hlwfzyj/hlwxzbg/hlwtjbg/201403/t20140305_46240.htm.

[2] Yan Liu, Liu Ying. The characteristics of university network public opinion and management countermeasures [J]. Journal of ideological education research, 2009.

[3] Xian Jixia Gu Muxian, Wu Hongyu etc. The campus network public opinion management mechanism analysis [J]. Journal of Guangxi youth cadre institute, 2009.

[4] Fang Zhengquan. Theory of connotation and significance of the construction of the harmonious campus [J]. Journal of higher education in Jiangsu province, 2007, (5).

[5] Wang Lingling. College students' network public opinion characteristics and guide [J]. Journal of ideological and theoretical education, 2006, (3). 